\title{
Fragility of Comparative Advantage in Higher Dimensions: An Experimental Investigation
}

\author{
Baboo M Nowbutsing \\ Department of Economics and Statistics, Faculty of Studies and Humanities, University of Mauritius, \\ Reduit, Republic of Mauritius \\ b.nowbutsing@uom.ac.mu
}

\begin{abstract}
In this study, an experimental analysis of the fragility of the law of the comparative advantage in higher dimensions is performed. Noussair et al (1995) invoked a trading environment similar to the $2 \mathrm{x}$ 2 Competitive Ricardian Model (CRM) and observed the law of comparative advantage. In this experiment, the same experimental setting is invoked however the number of goods and countries is increased. There were three countries and three goods, two countries were categorised as 'intermediate' comparative advantage while one as 'extreme' comparative advantage. However, the Jones (1961)'s criterion for optimal assignment was satisfied. The experimental findings reveal the following (1) both the autarky model and the competitive model are rejected as a representation of the data but the competitive model performs better than the autarky model (2) the CRM does not predict the production pattern (3) the CRM does not predict pattern of trade (4) output prices do not converge to the prediction of the theoretical model. Thus the results support the claim of Deardoff (2005).
\end{abstract}

Keywords: Competitive Ricardian Model; Comparative Advantage; Experiments; Trading Environment and Convergence.

\section{Introduction}

Noussair et al (1995) created an experimental environment motivated by the $2 \times 2$ Competitive Ricardian Model (CRM) and showed that the law of comparative advantage held in this setting. Deardorff (2005) argued that CRM generalises easily to either a two countries three goods setting or a three countries two goods setting. However, the comparative advantage does not hold when both number of countries and the number of goods are increased at the same time, for example in a three countries three goods setting. However, the generalisation to a three by three setting was illustrated by Jones (1961). He provided a complete specification of the patterns of specialisation and trade in the CRM with many goods and countries. He showed an efficient assignment* of countries to goods in a many-good, many-country CRM require minimisation of the product of countries' unit labour requirements. Specialisation is associated with low unit labour requirements where "low" must be interpreted in comparison to other goods since the model requires that each country produce something, and thus contributes at least one of its labour requirements to one of these goods.

The growing literature in experimental economics shows that market convergence generalise to a wide class of experimental economies, including those with multiple markets, small as well as large numbers of traders, robot traders or human traders, and markets with externalities. Although experimental economies converge towards equilibrium predictions, this process is not immediate. Convergence is achieved through a dynamic process that leads the variables in the economy towards equilibrium values. As experimental economies become more complex, the attainment of equilibrium becomes slower and less comprehensive. However, the equilibration process interacts with the specific interdependencies in different microeconomic structures to produce consistent and replicable results. There are many authors who have studied different complex environments including market interdependencies. Examples include Goodfellow and Plott (1990), who include production with derived demand; Chen and Plott (2002), who induced an exchange economy with two or more commodities; Lian and Plott (1998) who induce a small general equilibrium system with a circular flow of income; Noussair et al (2007) who created a large experimental environment to represent 3 countries trading in a perfectly competitive world; and Noussair and Powell (2008), who constructed experimental markets to observe behaviour of assets markets that experience a peak or trough in fundamentals.

\footnotetext{
* Jones (1961) defined an assignment as a pattern of complete specialisation and argued that there is a unique optimal assignment which is the one that lie on the world efficiency locus. An efficient/optimal assignment occurs when it is impossible to increase world output of any goods without reducing the output of at least one other good by moving labour from one assignment to the other.
} 
In this paper, a $3 \times 3$ CRM which satisfy the optimal assignment condition is invoked. The trading model is operationalised in a laboratory setting. The laboratory world is divided into three countries where each is characterised by its own labour endowment and production technology. There are three output goods $(X$, $Y$ and $Z$ ) which can be produced in any of the three countries at a predetermined rate. One input good, labour $(L)$ is required to produce any of the outputs and reside in each of the three countries. Labour is immobile among countries. International trade occurs when output goods produced in one country are sold in the other two countries. Markets exist for all output goods ( 3 in each country) and all input goods ( 1 in each country). Thus, there are 12 markets in operation. There is no market for currencies as the exchange rate is set to 1 . These markets will give an idea of the pattern of consumption, production and trade which occurs simultaneously in each country. Ultimately, the question that is addressed is: does the market system converges to the theoretical predictions when the Ricardian environment becomes more complex? Hence, this experiment checks for the robustness of the law of comparative advantage when both the number of goods and countries are increased.

The structure of the paper is as follows: Section 2 explores in more details the $3 \times 3$ CRM which is invoked in the laboratory; Section 3 illustrates the experimental parameters; the theoretical predictions are given in Section 4; Section 5 describes the statistical methodology; the results are reported in Section 6; Section 7 discusses efficiency. The conclusion is provided in section 8.

\section{Models}

\section{3 x 3 Competitive Ricardian Model}

In the $3 \times 3 \mathrm{CRM}$, there are three final goods, $X, Y$ and $Z$ which can be produced by a single input $L$. There are three countries which differ in their endowment of $L$. $L$, which is supplied in elastically, is mobile across sectors in a particular country but immobile across countries. The three countries are assumed to have different production function so that each has comparative advantage in the production of one of the goods. Assume that the constant labour costs of producing a unit of good $j(j=X, Y, Z)$ in country $i(i=1,2$, 3), i.e. $\mathrm{a}_{L j}{ }^{i}$ are as follows:

Table 1: Goods Triangle

\begin{tabular}{ccccc}
\hline & & \multicolumn{3}{c}{ Country } \\
& & $\mathbf{1}$ & $\mathbf{2}$ & $\mathbf{3}$ \\
\hline \multirow{3}{*}{ Goods } & $X$ & $\mathrm{a}_{L X}{ }^{1}$ & $\mathrm{a}_{L X}{ }^{2}$ & $\mathrm{a}_{L X^{3}}$ \\
& $Y$ & $\mathrm{a}_{L Y}{ }^{1}$ & $\mathrm{a}_{L Y}{ }^{2}$ & $\mathrm{a}_{L Y}{ }^{3}$ \\
& $Z$ & $\mathrm{a}_{L Z}{ }^{1}$ & $\mathrm{a}_{L Z}{ }^{2}$ & $\mathrm{a}_{L Z}{ }^{3}$ \\
\hline
\end{tabular}

In this case, how does one determine in which good country $i$ has comparative advantage? Mckenzie (1954) was among the first to extend the CRM of trade to the case of many goods and countries. An efficient pattern of production must satisfy two conditions, first the bilateral comparisons for all possible pairings of goods and countries and second minimisation of the product of labour coefficient. Country 1 will produce and export good $X$ if the following bilateral comparison is satisfied: $a_{L Z}{ }^{1} / a_{L X}{ }^{1}>a_{L Z}{ }^{3} / a_{L X}{ }^{3}$, i.e. it has bilateral comparative advantage in producing $X$ compared to country 3 and $a_{L Y}{ }^{1} / a_{L X}{ }^{1}>a_{L Y}{ }^{2} /$ $a_{L X}{ }^{2}$, a comparative advantage in good producing good $X$ compared to country 2 . Country 2 will produce good $Y$ if $a_{L X}{ }^{2} / a_{L Y}{ }^{2}>a_{L X}{ }^{1} / a_{L Y}{ }^{1}$ and $a_{L Z}{ }^{2} / a_{L Y}{ }^{2}>a_{L Z}{ }^{3} / a_{L Y}{ }^{3}$ and Country 3 will produce good $Z$ as $a_{L X}{ }^{3} /$ $a_{L Z}{ }^{3}>a_{L X}{ }^{1} / a_{L Z}{ }^{1}$ and $a_{L Y}{ }^{3} / a_{L Z}{ }^{3}>a_{L Y}{ }^{2} / a_{L Z}{ }^{2}$. McKenzie (1954) illustrates the concept of bilateral comparative advantage through the 'goods triangle'. Assume that the constant labour costs of producing a unit of $j$ in $i$ are as follows:

Table 2: Comparative Advantage Goods Triangle

\begin{tabular}{ccccc}
\hline & & \multicolumn{3}{c}{ Country } \\
\hline \multirow{3}{*}{ Good } & $X$ & 1 & 2 & 3 \\
& $Y$ & $1 / 4$ & 1 & 2 \\
& $Z$ & 1 & $1 / 3$ & $1 / 2$ \\
\hline
\end{tabular}


One can use these to rank the bilateral comparative costs in three lines as shown in figure $1 \mathrm{~A}$ where the numbers denote countries. If only $Z$ and $X$ are produced, then all countries produce $Z$. Country 1 has the highest bilateral comparative advantage in producing $X$ relative to $Z$, next is country 2 whereas country 3 has the lowest bilateral comparative advantage $(1 / 4<2<3)$. If only $X$ and $Y$ are produced, country 2 has the highest bilateral comparative advantage in producing $Y$ relative to $X$ and country 1 has the least $(1 / 3$ $<1 / 2<4$ ). If only $Y$ and $Z$ are produced, then country 3 has the highest bilateral comparative advantage in $Z$ relative to $Y$ and country 2 the least $(2 / 3<1<3 / 2)$. Thus, bilateral comparative advantage considerations reveal that country 1 will produce $X$, country 2 will produce $Y$ and country 3 will produce $Z$.

Figure 1A:

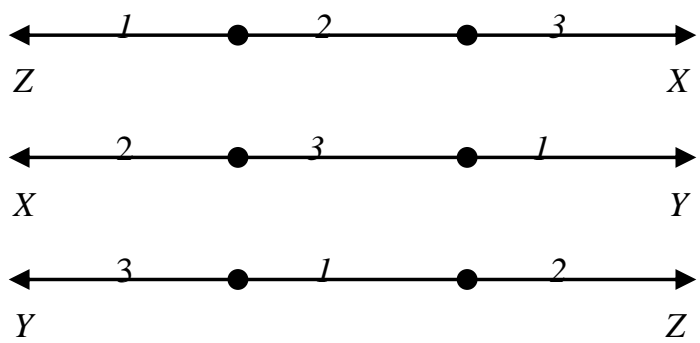

These lines represent the edge of the goods triangle shown in figure $1 \mathrm{~B}$.

\section{Figure 1B: Goods Triangle}

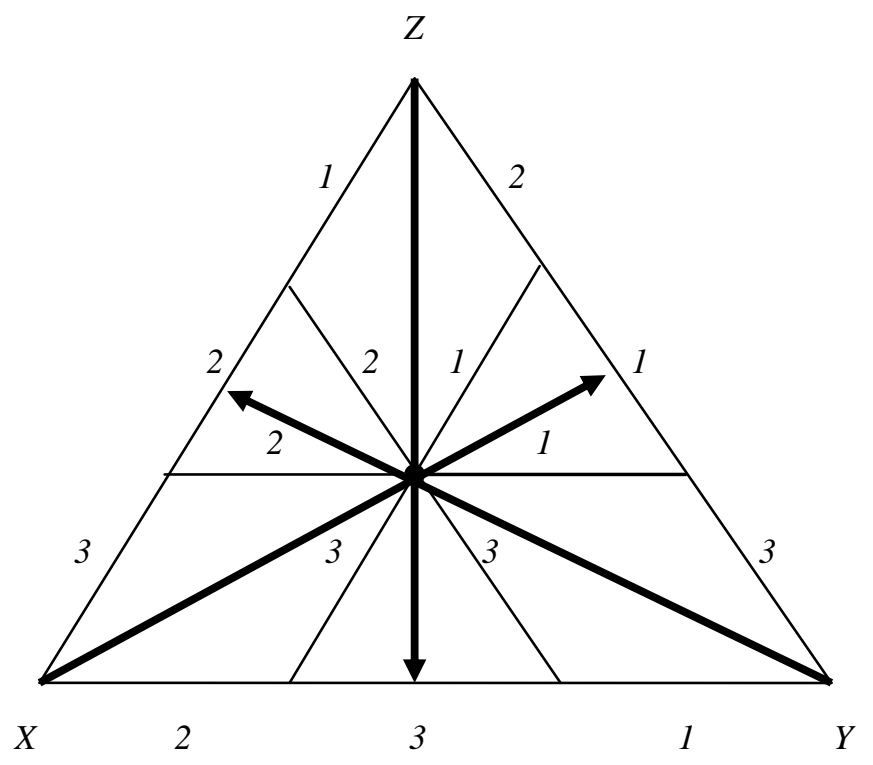

In addition to satisfying bilateral comparative advantage, an efficient optimal assignment pattern minimises the product of labour coefficients. Jones (1961)'s criterion for optimal assignment is

$$
\prod_{i=1}^{3} a_{L i}^{i}<\prod_{i=1}^{3} a_{L j}^{i} \text { for } j \neq i \text { and all } j \text { is different from each other }
$$

Consider figure 1B, at the $X$-origin, assume there is an increase in demand for $Y$ and $Z$ at the expense of $X$. The ordering of countries along the borders of the good triangle indicates country 1 is the last country to transfer resources from production of $X$ to $Y$ and $Z$. Similarly, if demand for either good $X$ and $Z$ increases, at the expense of $Y$, country 2 is the last country to pull resources out of production of $Y$. Country 3 is particularly good at producing $Z$ in the sense that if demand for $X$ and $Y$ relative to $Z$, country 3 is the last to move resources away from production of $Z$ either $X$ or $Y$. There are six possible assignments in which 
three goods are produced and the efficient one has $X$ produced by country $1, Y$ produced by 2 and $Z$ produced by 3 . In a competitive equilibrium, any commodity actively produced in a country must have unit labour costs equal to price so that profits are competed away. There is a simple general rule for locating the assignment that is efficient in its class. Reconsider the interior class in which each country is specialised completely to a different good. In the efficient specialisation, country 1 was assigned $X$, country $2 Y$ and country $3 Z$, so that:

$$
\begin{aligned}
& w^{1} a_{L X}^{1}=p_{X} \\
& w^{2} a_{L Y}^{2}=p_{Y} \text { or } w^{1} w^{2} w^{3} a_{L X}^{1} a_{L Y}^{2} a_{L Z}^{3}=p_{X} p_{Y} p_{Z} \\
& w^{3} a_{L Z}^{3}=p_{Z}
\end{aligned}
$$

where $w^{i}$ is country $i^{\prime}$ s wage rate. It is also require that

and

$$
\begin{aligned}
& w^{1} a_{L Y}^{1} \geq p_{Y} \\
& w^{2} a_{L Z}^{2} \geq p_{Z} \text { or } w^{1} w^{2} w^{3} a_{L Y}^{1} a_{L Z}^{2} a_{L X}^{3} \geq p_{X} p_{Y} p_{Z} \\
& w^{3} a_{L X}^{3} \geq p_{X}
\end{aligned}
$$

$$
\begin{aligned}
& w^{1} a_{L Z}^{1} \geq p_{Z} \\
& w^{2} a_{L X}^{2} \geq p_{X} \text { or } w^{1} w^{2} w^{3} a_{L Z}^{1} a_{L X}^{2} a_{L Y}^{3} \geq p_{X} p_{Y} p_{Z} \\
& w^{3} a_{L Y}^{3} \geq p_{Y}
\end{aligned}
$$

If the assignment that $X$ is produced by country $1, Y$ by 2 and $Z$ by 3 is efficient/ optimal the product $a_{L X}^{1} a_{L Y}^{2} a_{L Z}^{3}$ must not exceed $a_{L Y}^{1} a_{L Z}^{2} a_{L X}^{3}$ as well as the product $a_{L Z}^{1} a_{L X}^{2} a_{L Y}^{3}$. The first product is $1 / 36$, the second $1 / 2$ and the third $1 / 2$. Therefore, the CRM model predicts that countries 1,2 and 3 would produce exclusively $X, Y$ and $Z$ respectively and each of the three countries would be a net exporter of the good it produces. Several properties of figure 1B can be found in Jones (1985). This includes among others uniqueness of the optimal 'internal' assignments.

\section{Autarky Model}

Under autarky, goods are produced for home consumption only. The autarky model is useful because it characterises one benchmark of the potential behaviour a system might exhibit. There is no complete specialisation. All countries produce the three goods in different quantities, there are no international trade. However, the wage-price ratios are identical to that of the competitive model.

\section{Experimental Design}

\section{Parameters}

A generalized CRM with three countries and three goods motivates the experimental environment. Trade in all markets followed the continuous double auction rules that were implemented through the MUDA software, details of which are available in Plott (1991) and Plott and Gray (1990). Table 1 shows the experimental parameters. A quadratic and additive separable utility function is assumed for both the consumers and producers ${ }^{\dagger}$. The idea of separability is of fundamental importance. If utility is directly additive, then the marginal utility of any good varies with the quantity of that good alone. This representation of utility is also consistent with the goods being normal. In addition, given any income, the

† Assume that $U(a)$ is well behaved if it is defined, strictly monotonic, and twice continuously differentiable on the nonnegative orthant $a \geq 0$. Then, $\mathrm{U}(a)$ is additively separable if it can be written as $U(a)=U\left(a^{1}, \ldots . a^{T}\right)=\sum f^{t}\left(x^{t}\right), \quad T>2$ in an appropriate normalization. 
ratio of the income elasticity to its price elasticity is taken to be constant. Further, it also makes it easy to determine redemption values of consumers. Each country has an equal number of producers and consumers and is endowed with a given amount of labour. Countries differ in their level of endowment and production technologies. Total endowment in each country is four times the amount listed in the table.

The experiment consists of three "countries" (1,2 and 3), three final goods: $X, Y$ and $Z$ - one factor, labour denoted by $L$. There are two types of agents in each country: Type C (Consumers) and Type P (Producers). Furthermore agents are divided equally among countries (4 each) and each has equal number of $C$ and $P$ agents. $L$ is immobile among countries whereas $X, Y$ and $Z$ can be traded no matter where they are produced.

Table 3: Experimental Parameters

\begin{tabular}{lccc}
\hline Preferences: & Country 1 & Country 2 & Country 3 \\
$U(X, Y, Z)=600 X-45 X^{2}+720 Y-45 Y^{2}+840 Z-45 Z^{2}$ & & & \\
\hline $\begin{array}{l}\text { Endowments of input factor }(L): \\
\text { Consumers }\end{array}$ & 2 & 3 & 4 \\
Producers & & 1 & 1 \\
Number: & 2 & 2 & \\
Consumers & 2 & 2 & 2 \\
Producers & 6 & 8 & 10 \\
Total Endowment & $X=4 L$ & $X=L$ & $X=L$ \\
Production & $Y=L$ & $Y=3 L$ & $Y=2 L$ \\
& $Z=L$ & $Z=2 L$ & $Z=3 L$ \\
\hline
\end{tabular}

The market system works as follows: Type $\mathrm{C}$ are owners of $L$ and have induced preferences for consuming $X, Y$ and $Z$. So they sell $L$ to Type $\mathrm{P}$ in their respective country and then buy units of $X, Y$ and $Z$ in any country. Type $\mathrm{P}$ traders buy $L$ from Type $\mathrm{C}$ in their own countries. Then, they use $L$ to produce $X, Y$ and $Z$, according to their respective production schedule, which they sell to consumers in all three countries. Type $\mathrm{C}$ traders get utility from consumption of goods $X, Y$ and $Z$ and from profits made in market activities. Any units of $X, Y$ and $Z$ bought by Type $C$ agents are assumed to be consumed. The redemption value sheet determines the amount Type $C$ agents receive through consumption and are given in Appendix 1. For the first unit of $X$ that Type $C$ consumes in a trading period, he/she receives the amount listed on his/her Redemption Value Sheet ( In this case 600, first row in the $X$ unit value column ). Type P gain utility from production /trading activities only. Any units of $L$ not used to produce goods $X / Y / Z$ are worthless to Type $P$ agents. Similarly any unit of $X, Y$ and $Z$ not sold is valueless.

Market transactions (i.e. buying and selling) in the experimented were done using an experimental currency namely 'franc'. To facilitate trading, each subject was given 100,000 francs at the start of each experiment. At the end of the experiment subjects were paid according to a conversation rateł. At the end of each period, subjects filled a Record Sheet to record the profit made in a particular period. Type P's record sheet consists of one section, trading which is the cash on hand at the end of the period minus the cash on hand at the beginning of the period. Type C's record sheet consists of two sections, trading and consumption. Consumption records the units consumed and earnings made from those units consumed. Total profits are given by net change in cash on hand and total earnings made from consumption.

Figure 2 shows the operation of the market system. The upper part shows the circular flow in country 2 , the lower left and the lower right show the circular flows of countries 1 and 3 respectively. Output markets were numbered 1 to 9 . Markets $1 / 2 / 3$ denote market $X / Y / Z$ in country 1 . Markets $4 / 5 / 6$ denote

\footnotetext{
* The conversation rate was 3000 francs to $£ 1$ for some experiments and 4000 francs to $£$ for other experiment.
} 
market $X / Y / Z$ in country 2 . Markets $7 / 8 / 9$ denote market $X / Y / Z$ in country 3 . Markets $10 / 11 / 12$ denote labour market in countries 1,2 and 3 respectively. Trade occurs when output goods are sold to agents in countries where production of these output goods did not take place and since labour is immobile among countries, this implies market restrictions are as follows:

Country 1- Type C: Market 11 and 12; Type P - Market 4, 5, 6, 7, 8, 9, 11 and 12. Country 2- Type C: Market 10 and 12; Type P - Market 1, 2, 3, 7, 8, 9, 10 and 12. Country 3- Type C: Market 10 and 11; Type P - Market 1, 2, 3, 4, 5, 6, 10 and 11.

\section{Figure 2: The Market System}

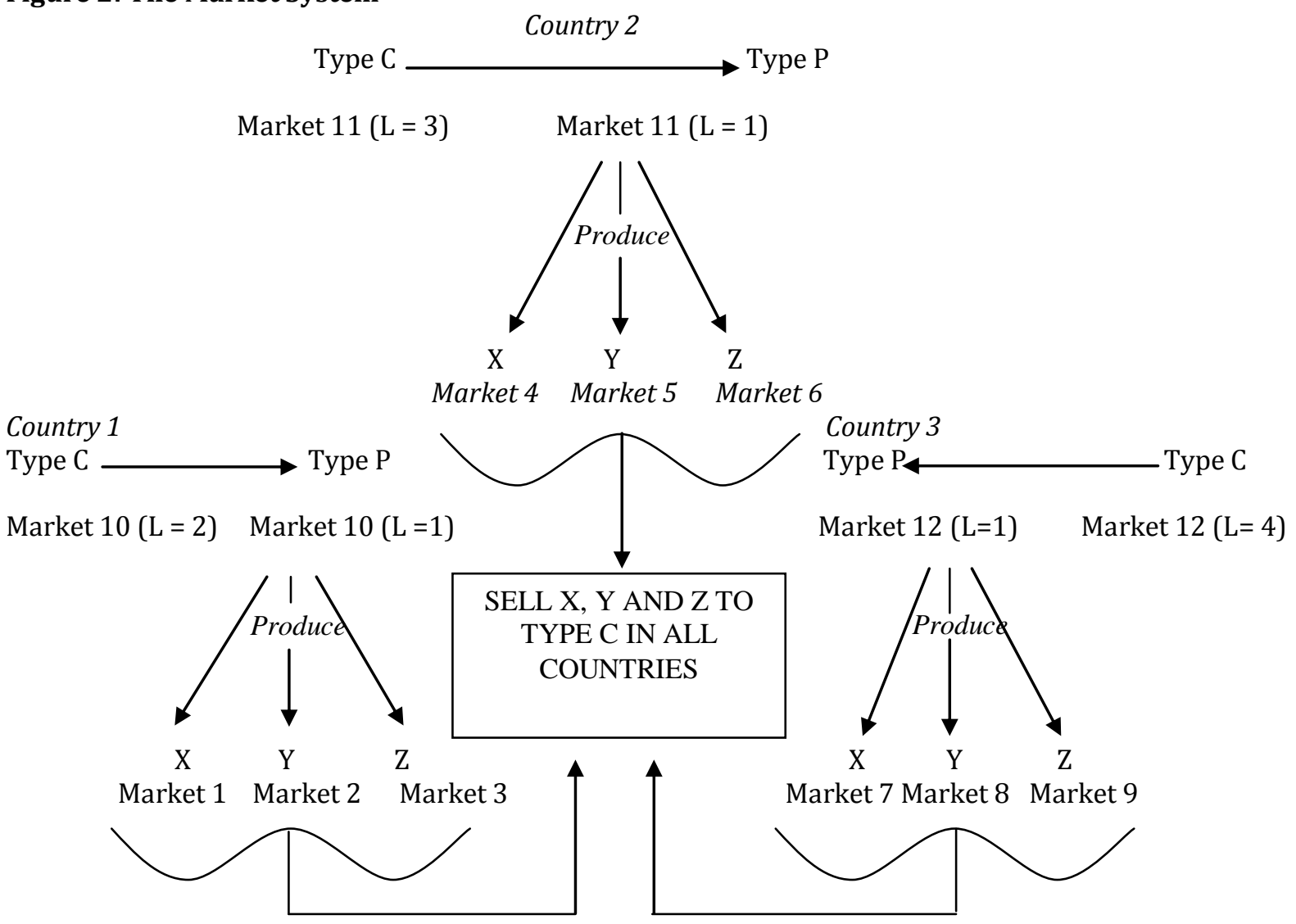

\section{Procedures}

Five experiments (Experiment 1- Experiment 5) were conducted in the CeDEx laboratory at the University of Nottingham. The experiments involve 12 subjects (4 in each country). Subjects were undergraduates from the University of Nottingham. Most were non - economics students. Subjects had training in the use of MUDA prior to the experiment, for which they were paid a fixed fee of $£ 5$. Subjects were not allowed to participate in more than one experiment. Each experiment was divided into 5 periods of 10 minutes. Once assembled for the first time, subjects were randomly assigned as either Type $\mathrm{C}$ agents or Type $\mathrm{P}$ agents and kept the same role over subsequent periods. Instructions were given to both types. The instructions consisted of eight sections. These gave information about: subject's type and number of goods in the computerized market; information about endowment and cash on hand; the operation of the market system; information about the production schedule and redemption values; information about trading profits, earnings and market restrictions. Full details of these instructions are given in Appendix 2. Basic information about MUDA included how to buy/ sell units, what numbers in the boxes meant and transformation. The first period of Experiment 1 was a practice session where accounting records were checked carefully for errors and subjects were reminded of the production and consumption process. In later periods and sessions spot checks were undertaken to verify accounting information. Subjects were also asked to check changes in cash on hand, endowments and contract history of the experiment using several keystrokes. The redemption values and production schedule were the same for each period; subjects received new endowments at the beginning of each period. 


\section{Theoretical Predictions}

Predictions about two environments are made namely: the autarky environment where countries only produce for self- consumption and the trading environment based on the $3 \times 3 \mathrm{CRM}$.

\section{The Competitive Ricardian Environment}

If trade occurs among the three countries, given labour endowments, comparative advantage dictates that country 1 produces and exports only $X$, country 2 produces and exports only $Y$ and country 3 produces and exports $Z$. Substituting labour endowment of $X, Y$ and $Z$ of country 1,2 and 3 in their respective production function gives total production. The utility function is differentiated to get marginal utilities of each good, from which the aggregate demand for the whole system can be obtained and thus free trade prices. Input prices equal their marginal revenue. Net exports are derived from the excess demand equations in each country evaluated at the competitive prices. The theoretical derivations are available upon request from the author.

Table 4: CRM Predictions

\begin{tabular}{cccc}
\hline Variables & Country 1 & Country 2 & Country 3 \\
\hline Production & & & - \\
$X$ & 24 & - & - \\
$Y$ & - & 24 & 30 \\
$Z$ & - & - & \\
Export & & & - \\
$X$ & 16 & - & - \\
$Y$ & - & 16 & 20 \\
$Z$ & - & - & - \\
Prices & & & - \\
$X$ & 240 & - & 390 \\
$Y$ & - & 360 & 1170 \\
$Z$ & - & - & \\
$L$ & 960 & 1080 & \\
\hline
\end{tabular}

\section{The Autarky Environment}

In this environment, ach country produces all 3 goods. Prices of all goods would be different in the three countries and. Also, there are no payments-imbalances such that the total expenditure spent on goods $X, Y$ and $Z$ is equal to the total income earned by labour. The derivation of the predictions for the autarky environment is derived in a similar manner as the CRM.

Table 5: Autarkic Predictions

\begin{tabular}{cccc}
\hline Variables & Country $\mathbf{1}$ & Country 2 & Country $\mathbf{3}$ \\
\hline Production & & & \\
$X$ & 12 & 1 & 2 \\
$Y$ & 1.5 & 12 & 6 \\
$Z$ & 1.5 & 6 & 15 \\
Prices & & & \\
$P_{X}$ & 60 & 615 & 510 \\
$P_{Y}$ & 652.5 & 180 & 450 \\
$P_{Z}$ & 772.5 & 570 & 145 \\
$P_{L X}$ & 240 & 615 & 510 \\
$P_{L Y}$ & 652.5 & 540 & 900 \\
$P_{L Z}$ & 772.5 & 570 & 4950 \\
\hline
\end{tabular}




\section{Efficiency}

Efficiency measures the extraction of social surplus. Following, Smith (1962), efficiency of a market is calculated as the total profit earned by all agents as a percentage of the maximum total profit that could be earned if trading occurred at equilibrium. In this case, the market system is $100 \%$ efficient in a given period if and only if competitive equilibrium is attained. To calculate the level of efficiency in a particular period, the total profits made by both Type $\mathrm{C}$ and Type $\mathrm{P}$ traders in this particular period as a proportion of the competitive equilibrium profit are compared.

Based on the theoretical predictions, the following hypotheses are tested:

Hypothesis 1: The competitive model is an accurate representation of the general data Hypothesis 2: Aggregate production patterns converge to the predictions of the CRM. Hypothesis 3: The law of comparative advantage accurately predicts trade pattern Hypothesis 4: Individual consumption converges to the predictions of CRM.

Hypothesis 5: Output prices converge towards the predictions of CRM.

Hypothesis 6: Input / Output price ratio converges toward the marginal physical product.

\section{Statistical Methodology}

There are many different definitions of price/quantity convergence in the double auction literature ${ }^{4}$. In this experiment, it is important to account for within and across period changes as the CRM is a static equilibrium model whereas the data are generated by a dynamic process. To check for convergence in the variable of interest, the following simple statistical dynamic model, called Ashenfelter-El-Gamal model used first in Noussair et al. (1995), is invoked.

$$
A_{i t}=B_{11} D_{1}\left(\frac{1}{t}\right)+\ldots \ldots+B_{1 i} D_{i}\left(\frac{1}{t}\right)+\ldots . . B_{1 n} D_{n}\left(\frac{1}{t}\right)+B_{2}\left(\frac{t-1}{t}\right)+u_{i t}
$$

$A_{i t}$ is the variable of interest in period $t$ for experiment $i, i=1 \ldots n$. $D_{i}$ are dummy variables that take a value of 1 for experiment $i$, and 0 otherwise. The random error $u_{i t}$ is distributed normally with zero mean. Assume the variable of interested in production of $Y$; when $t=1$, production of $Y$ in experiment $i$ equals $B_{1 i}$ which can be interpreted as the initial production of $Y$ for experiment $i$. However, its impact reduces over time, as $\left(\frac{1}{t}\right)$ tends toward zero e when $t$ increases. Compared to $B_{1 i}$, when $t$ increases the impact of $B_{2}$ increases as $\left(\frac{t-1}{t}\right)$ gets larger. Thus, the coefficient $B_{2}$ can be interpreted as the common asymptote of the variable production of $Y$. To observe strong convergence of variable $A_{i t}$, it suffices to test whether or not the estimates of $B_{2}$ are significantly different from the predictions of the model. If not, it is said that the variable is strongly converging to the predicted values. However, as pointed out by Noussair et al (1995), weak or partial convergence can also be observed. Weak convergence is present if $B_{2}$ 's are quantitatively closer to the predictions than $B_{1 i}$. Since the number of experiments is 5 , the model is:

$$
\begin{aligned}
A_{i t}= & B_{11} D_{1}\left(\frac{1}{t}\right)+B_{12} D_{2}\left(\frac{1}{t}\right)+B_{13} D_{3}\left(\frac{1}{t}\right)+B_{14} D_{4}\left(\frac{1}{t}\right)+B_{15} D_{5}\left(\frac{1}{t}\right)+B_{2} \frac{t-1}{t} \\
& +u_{i t}
\end{aligned}
$$

\section{Results}

At the end of each experiment, a series of input and output prices are generated. These include ask prices, bid prices and contract prices. Figures 3 (a), (b) and (c) show the output contract time series for countries 1,2 and 3 respectively. Figures $4(a, b$ and $c$ ) shows the input contract time series for countries 1,2 and 3 respectively. The data are from Experiment 3.

\footnotetext{
${ }^{4}$ For example, Gode and Sunder (1993) argue that convergence occurs if the final market price is closer to the predicted price than early price. According to Gjerstad and Dickhaut (1998), convergence occurs if, after several periods, the mean deviation of all trades from equilibrium is small.
} 
Figure 3: Output Price Time Series- Experiment 3
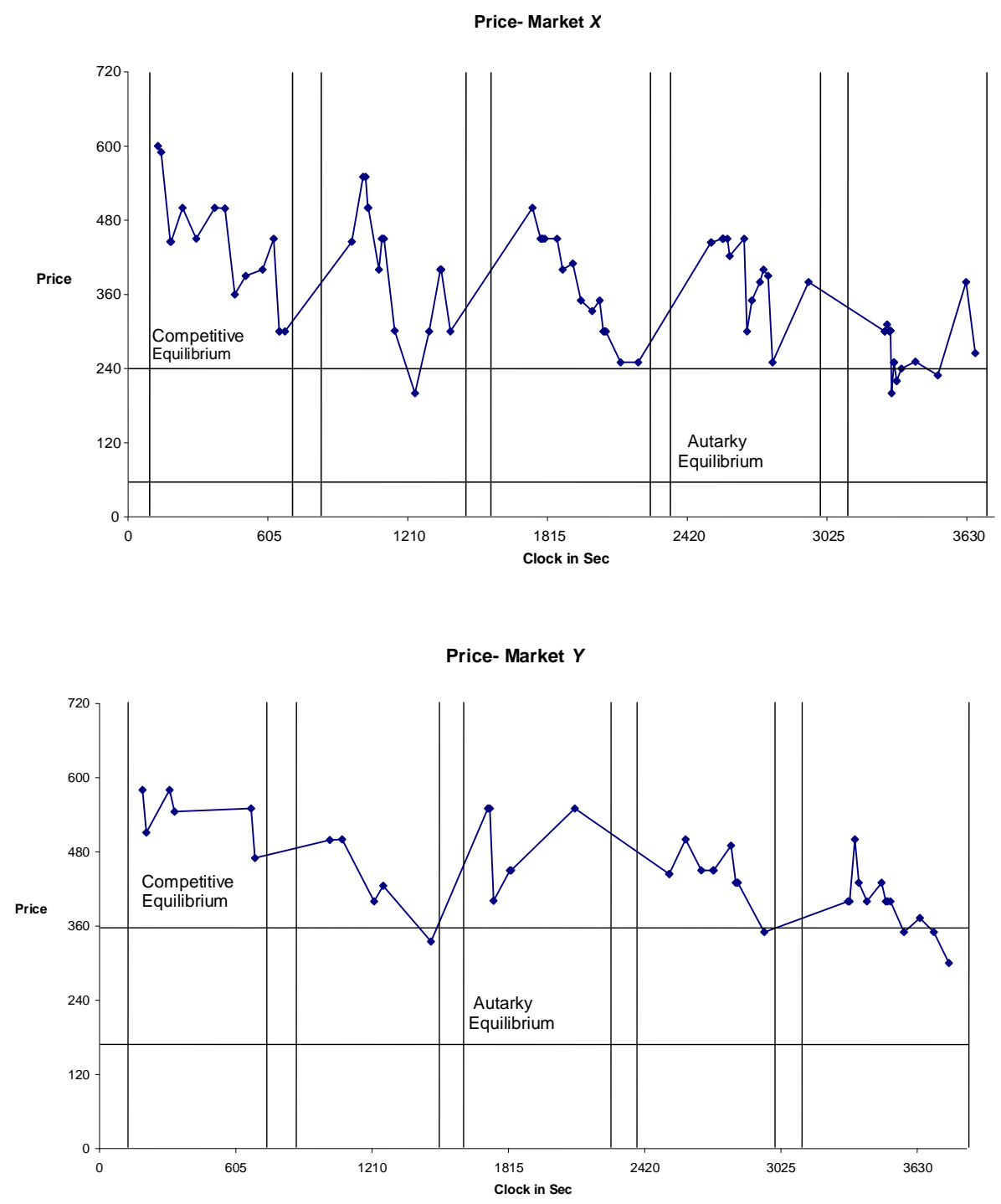

Price- Market Z

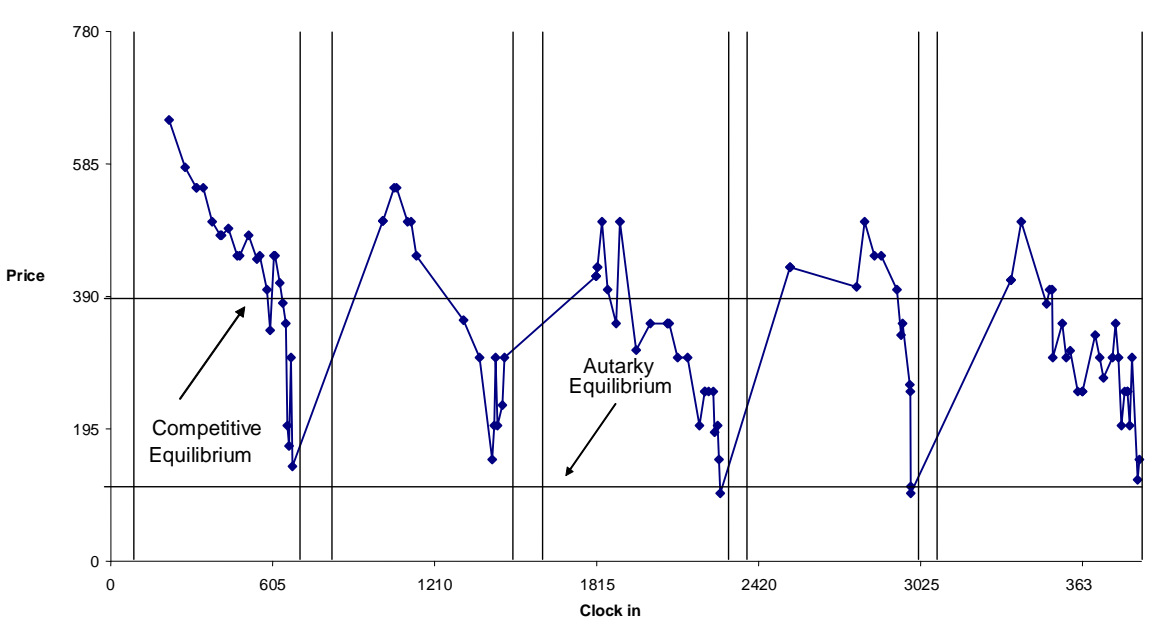


Figure 4: Input Price Time Series- Experiment 3
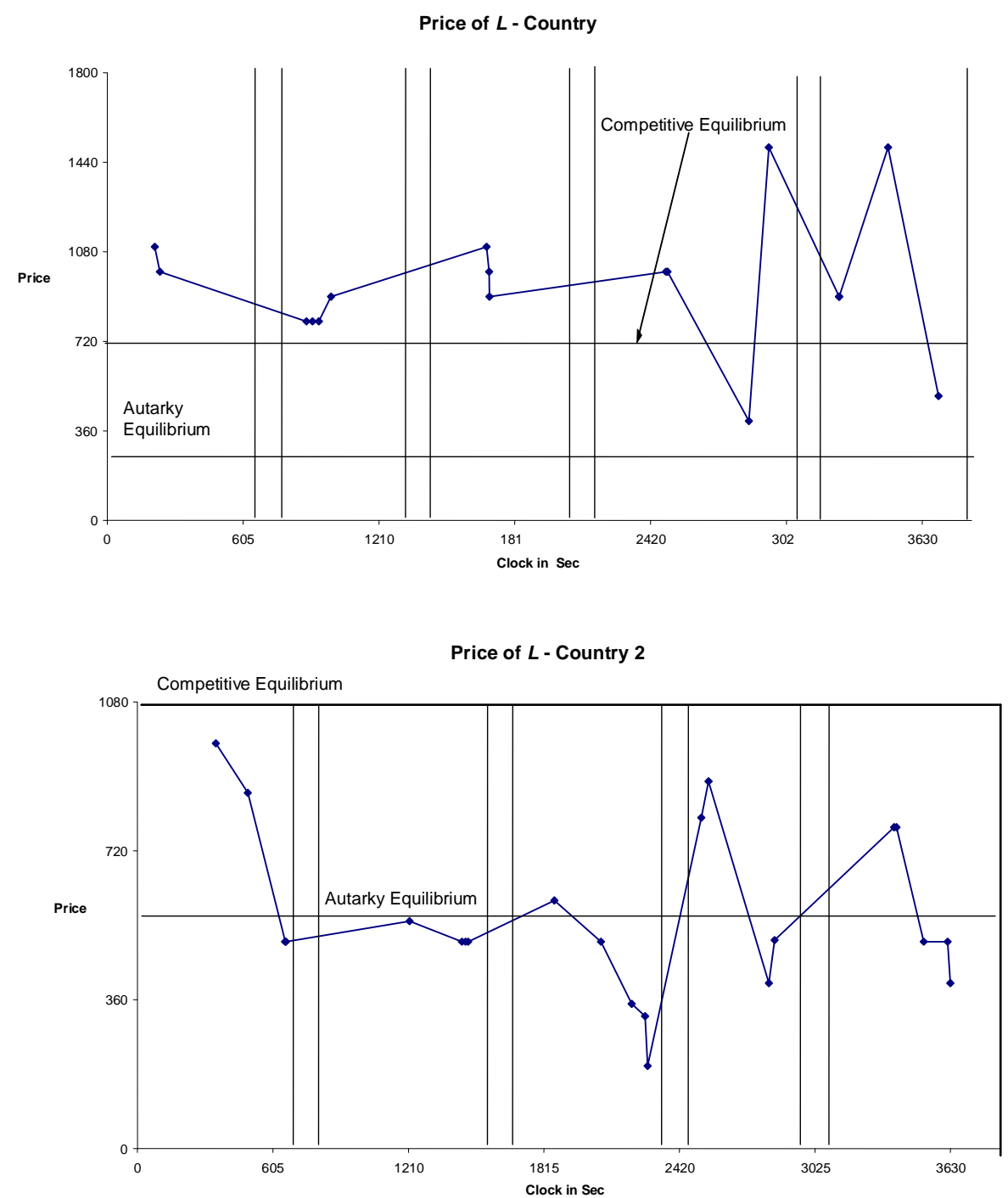

(b)

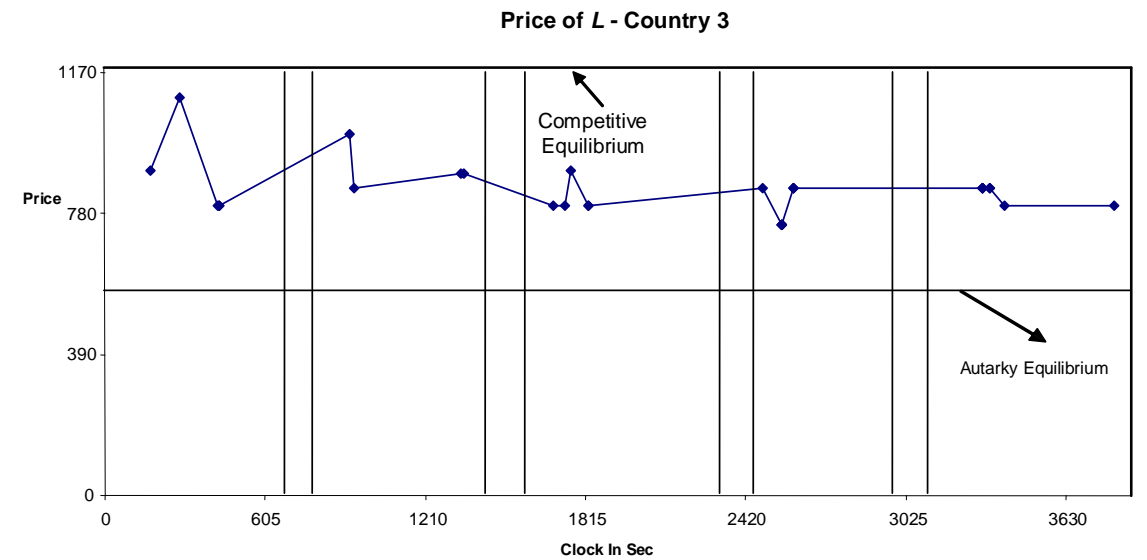

(c)

The $x$-axis denotes time measured in sec and gives the exact second of accepted bids or asks. The $y$-axis denotes prices. The vertical lines show the beginning and end of each period. The first line shows the beginning of the first period whereas the second denotes the end of period one. The gap between two lines shows the time interval between the end of a period and start of another. Nothing happens during this interval and subjects filled their record sheets. Spot checks were also undertaken. Although all observed contract prices do not automatically clustered towards the competitive equilibrium, there is an 
indication of convergence in some markets. In later periods of the experiment, prices in market $X$ and $Y$ (figure 3) (b) and (c)) converge towards the competitive equilibrium. Prices in market $Z$ experience slight convergence to the competitive equilibrium in period 5. Compared to outputs prices, input prices have a tendency to be both below the competitive equilibrium for country 2 and 3 whereas there is slight indication of convergence in the case of country 1 . From the experiment 3 it is concluded that there is tendency for the competitive equilibrium price to be a better predictor in output than in input markets.

Table 6: Convergence Patterns over time Production, Exports and Market Prices

\begin{tabular}{|c|c|c|c|c|c|c|c|c|c|c|c|}
\hline \multirow{3}{*}{$\begin{array}{c}\text { Dependent } \\
\text { Variables }\end{array}$} & \multicolumn{11}{|c|}{$Y=B_{11} D_{1} 1 / t+\ldots \ldots \ldots \ldots \ldots \ldots . . . B_{15} D_{5} 1 / t+B_{2}(t-1) / t+u$} \\
\hline & \multirow{2}{*}{$B_{11}$} & \multirow{2}{*}{$B_{12}$} & \multirow{2}{*}{$B_{13}$} & \multirow{2}{*}{$B_{14}$} & \multirow{2}{*}{$B_{15}$} & \multirow{2}{*}{$\boldsymbol{B}_{2}$} & \multicolumn{2}{|c|}{$\begin{array}{l}\text { Competitive } \\
\text { Equilibrium }\end{array}$} & \multicolumn{2}{|c|}{ Autarky } & \multirow[t]{2}{*}{$\mathrm{R}^{2}$} \\
\hline & & & & & & & Predictions & Sig & Predictions & Sig & \\
\hline \multicolumn{12}{|l|}{$\begin{array}{l}\text { Production: } \\
\text { Country } 1\end{array}$} \\
\hline \multirow[t]{2}{*}{ X } & 12.55 & 15.28 & 22.39 & 14.19 & 17.37 & 19.23 & 24 & Ns & 12 & $<0.001$ & 0.62 \\
\hline & 4.94 & 2.37 & 4.73 & 4.97 & 4.16 & 2.08 & & & & & \\
\hline \multirow[t]{2}{*}{$Y$} & 0.64 & 0.87 & 0.95 & 1.18 & 0.7 & 0.37 & 0 & Ns & 1.5 & $<0.001$ & 0.57 \\
\hline & 0.98 & 0.45 & 0.39 & 0.52 & 0.84 & 0.27 & & & & & \\
\hline \multirow[t]{2}{*}{$Z$} & 0.68 & 0.72 & 1.02 & 1.25 & 1.02 & 0.23 & 0 & Ns & 1.5 & $<0.001$ & 0.66 \\
\hline & 0.87 & 0.78 & 0.24 & 0.71 & 0.24 & 0.23 & & & & & \\
\hline \multicolumn{12}{|l|}{ Country 2} \\
\hline \multirow[t]{2}{*}{$X$} & 1.6 & 2.7 & 0.14 & 0.56 & 0.12 & 0.39 & 0 & Ns & 1 & $<0.05$ & 0.62 \\
\hline & 1.7 & 3.56 & 0.52 & 1.55 & 0.54 & 0.53 & & & & & \\
\hline \multirow[t]{2}{*}{$Y$} & 11.73 & 9.99 & 9.68 & 8.87 & 17.41 & 13.93 & 24 & $<0.001$ & 12 & ns & 0.57 \\
\hline & 9.17 & 3.04 & 6.67 & 8.67 & 2.56 & 2.14 & & & & & \\
\hline \multirow[t]{2}{*}{$Z$} & 3.76 & 3.44 & 4.67 & 5.67 & 6.03 & 4.42 & 0 & $<0.001$ & 6 & ns & 0.66 \\
\hline & 0.87 & 1.87 & 2.37 & 4.64 & 5.59 & 1.06 & & & & & \\
\hline \multicolumn{12}{|l|}{ Country 3} \\
\hline$X$ & 2.27 & 0.26 & 0.2 & 0.48 & 0.054 & 0.55 & 0 & Ns & 2 & $<0.05$ & 0.6 \\
\hline & 2.01 & 0.76 & 0.63 & 1.35 & 0.3 & 0.34 & & & & & \\
\hline$Y$ & 0.18 & 6.54 & 1.89 & 2.14 & 2.37 & 7.1 & 0 & $<0.001$ & 6 & ns & 0.81 \\
\hline & 4.96 & 1.6 & 1.5 & 0.94 & 1.38 & 1.27 & & & & & \\
\hline$Z$ & 18.39 & 15.04 & 25.43 & 14.67 & 24.71 & 18.82 & 30 & $<0.001$ & 15 & ns & 0.93 \\
\hline & 9.86 & 8.32 & 5.11 & 7.3 & 6.3 & 2.69 & & & & & \\
\hline Net Exports: & & & & & & & & & & & \\
\hline X & 7.9 & 4.23 & 8.19 & 4.47 & 7.2 & 13.24 & 16 & Ns & 0 & $<0.05$ & 0.62 \\
\hline & 10.8 & 2.64 & 7.6 & 4.27 & 3.65 & 2.14 & & & & & \\
\hline$Y$ & 1.65 & 3.56 & 1.9 & 8.16 & 13.97 & 7.74 & 16 & $<0.001$ & 0 & $<0.05$ & 0.57 \\
\hline & 4.02 & 4.11 & 3.31 & 5.13 & 1.63 & 1.85 & & & & & \\
\hline$Z$ & 1.65 & 11.49 & 18.97 & 9.23 & 19.17 & 10.14 & 20 & $<0.001$ & 0 & $<0.05$ & 0.66 \\
\hline & 3.86 & 4.45 & 1.68 & 1.1 & 2.44 & 1.46 & & & & & \\
\hline Market Prices: & & & & & & & & & & & \\
\hline Country & & & & & & & & & & & \\
\hline$X$ & 508.06 & 526.07 & 448.6 & 440.8 & 286.3 & 327.2 & 240 & $<0.001$ & 60 & $<0.05$ & 0.9 \\
\hline & 88.2 & 88.01 & 30.64 & 39.2 & 99.4 & 23.5 & & & & & \\
\hline$L$ & 2069.7 & 1501.6 & 1074.6 & 465.7 & 664.7 & 794.9 & 960 & Ns & 240 & $<0.05$ & 0.66 \\
\hline & 1850 & 349.4 & 563.6 & 571 & 190 & 250 & & & & & \\
\hline Country 2 & & & & & & & & & & & \\
\hline$Y$ & 855.64 & 852.55 & 486.354 & 418.53 & 313.1 & 491.1 & 360 & $<0.05$ & 180 & $<0.005$ & 0.82 \\
\hline & 92.32 & 521.96 & 63.7 & 75.36 & 61.79 & 62.45 & & & & & \\
\hline$L$ & 1369 & 1591.6 & 464.65 & 576.59 & 584.3 & 801.8 & 1080 & $<0.05$ & 540 & $<0.05$ & 0.86 \\
\hline & 640.29 & 222.94 & 204.0 & 205.76 & 103.09 & 117.25 & & & & & \\
\hline Country 3 & & & & & & & & & & & \\
\hline$Z$ & 1074.7 & 505.98 & 323.843 & 388.51 & 333.6 & 476.7 & 390 & $<0.05$ & 165 & $<0.001$ & 0.89 \\
\hline & 428.47 & 38.66 & 98.72 & 80.79 & 73.93 & 44.86 & & & & & \\
\hline$L$ & 3364.8 & 1484.3 & 789.8 & 635.9 & 833.7 & 969.5 & 1170 & Ns & 495 & $<0.005$ & 0.91 \\
\hline & 547.04 & 119.51 & 122.28 & 158.53 & 129.85 & 154.81 & & & & & \\
\hline
\end{tabular}


Result 1: Both the autarky model and the competitive model are rejected as a representation of the data but the competitive model performs better than the autarky model.

Table 6 reports the estimates of the parameters of the econometric model described in section 5 for production, net export and market prices respectively. Estimates of the origin of each experiment, as captured by $B_{1 i}$, are reported as well as the common asymptote (captured by $B_{2}$ ) for each variable. Standard errors, given in italics, are corrected for heteroscedasticity (to account for stabilization, which would decrease the variance of the error terms for later periods in the sessions) as well as serial correlation. $\mathrm{R}^{2}$ is also reported for each equation. The sig column give the significance level at which the null hypothesis is rejected, ns denotes non-significant. The null hypothesis being the asymptote of a particular variable is the same as its theoretical prediction. This hypothesis cannot be rejected. The hypothesis that a variable converges to its competitive equilibrium cannot be rejected if the $B_{2}$ is not statistically different from the predicted value. The models are accepted as appropriate representations of the data if sig for all the variables are non-significant (ns).

Predictions are made for 12 quantity variables and for 6 price variables. For the competitive model, $B_{2}$ is not statistically different from the predicted value in 8 cases out of 18 . The autarky model on the other hand succeeds to predict 4 variables out of the 18 . Thus, both the autarky model and the competitive model are rejected as a representation of the data but the competitive model performs considerably better than autarky.

\section{Result 2: The CRM does not predict production patterns.}

The CRM predicts that country 1 will devote all its endowments to production in sector $X$. Thus, country 1 will not produced either $\mathrm{Y}$ or $\mathrm{Z}$ at any particular time. From table 4, production of $X$ in country 1 as captured by $B_{2}$ is 19.2 units compared to 24 . A test of significance revealed that the hypothesis that the asymptote, $B_{2}$ is statistically different form the predicted value cannot be reject ted. This indicates proof of strong convergence.

From table 6, it can be deduced that as more experiments are carried out production of $Y$ and $Z$ inclined towards zero. $B_{1 i}$ 's are nearer to zero in later experiments indicating presence of weak convergence. Furthermore, there is also strong convergence; $B_{2}$ 's are not statistically different from zero. Compared to the CRM, the autarky model performed badly. There are sign of neither strong nor weak convergence when it comes to production of $X, Y$ and $Z$. The asymptotes of the production variables are significantly different from the predicted values of the autarky model. At $p<0.001$, the null hypothesis that the asymptote $B_{2}$ 's is similar to the predictions of the autarky model is rejected. From these two observations, the conclusion is that the CRM predicts the pattern of production in country 1.

From table 6, there is no evidence of strong convergence in production of $Y$ and $Z$ for country 2. $B_{2}$ 's are statistically different from the equilibrium values. Production of $Y$ is 13.93 units as opposed to 24 units and production of $Z$ is 4.42 units as opposed to zero. At $p<0.001$, the null hypothesis that the asymptote $B_{2}$ 's is similar to the predictions of the CRM model is rejected. Similarly, $B_{1 i}$ are quantitatively closer to the predicted value indicating absence of weak convergence. Similar conclusions are reached when production in country 3 is considered. Production of $Y$ is 7.1 units as opposed to zero and production of $Z$ is 18.82 as opposed to 30 units. However, the CRM accurately predicts the level of production of good $X$ in both countries. Based on the $t$-test conducted, there is evidence of strong convergence. The hypothesis that production in later periods converges towards zero cannot be rejected at $p<0.001$ level of significance. Surprisingly, the autarky model is a better predictor for production of $Y$ and $Z$ in countries 2 and 3. Thus, there is proof of strong convergence. In country 2, production of $Y$ is 13.93 units as opposed to 12 and production of $Z$ is 4.42 units as opposed to 6. In country 3, production of $Y$ is 7.1 units as opposed to 6 and production of $Z$ is 18.82 units as opposed to 15 .

\section{Result 3: The law of comparative advantage fails to predict the pattern of trade.}

With reference to table 4, the observed value of net exports of good $X$ is 13.24 as opposed to 16 units. Statistically, the asymptote of net exports of good $X$ is not different from the prediction of the CRM. Table 4 also reveals that $B_{1 i}>B_{2}$ (for $i=3$ to 5 ) indicating that the regression line is negatively sloped and experiment $i$ converges from above. Thus, the flow of international trade is not only in the direction predicted by comparative advantage but the magnitude is converging to the predicted value of the 
competitive environment. Result 2 and 3 suggest that the pattern of production and trade are consistent with the directions predicted by the CRM for country 1.

From Result 2, the inference that the CRM predicted production quantities for countries 2 and 3 are not consistent with the observed asymptote values. From table 4, net exports of $Y$ and $Z$ are respectively 7.74 and 10.14 units compared as opposed to 16 and 20. The null that the observed values are similar to the predicted value is rejected at $p<0.001$, indicating no evidence of strong convergence. Similarly, no evidence of weak convergence is found. Results 2 and 3 indicate that the CRM fails to predict both production and net export quantities for countries 2 and 3.

McKenzie (1954) and Jones (1961) show that when the dimensionality of goods and countries in the CRM is increased, countries will produce and export those goods where the bilateral comparisons of unit labour coefficient holds for all possible pairings of goods and the product of the labour requirement in efficient assignment of goods must be less that the corresponding product of all possible assignments that allocate the same number of countries to each commodity as the efficient assignment. In this case, this generalization implies that country 1 will produce and export good $X$; country 2 will produce and export $Y$ and country 3 will produce and export $Z$. The results obtained reveal existence of complete specialisation for good $X$ but not for good $Y$ and $Z$. Similarly, while country 1's net exports of $X$ are in accordance with the predictions of the CRM this is not the case for net exports of $Y$ and $\mathrm{Z}$.

\section{Result 4: Individual Consumption of $X, Y$ and $Z$ converge to the predicted values of the CRM.}

Table 7: Average Individual Consumption

\begin{tabular}{crrrrr}
\hline Good & 1 & 2 & 3 & 4 & 5 \\
$X$ & 2 & 2.9 & 2.9 & 2.5 & 3.2 \\
$Y$ & 1.7 & 1.1 & 1.4 & 1.5 & 2.8 \\
$Z$ & 3.1 & 2.3 & 2.3 & 2.4 & 3.6 \\
\hline
\end{tabular}

Table 7 gives the average individual consumption per period. It can be seen that individual consumption in Period 5 is higher than in other periods. However, individual consumption in any period is not equal to the theoretical prediction of 4,4 and 5 units of goods $X, Y$ and $Z$ respectively. The mean deviation and standard deviation statistics are used to analyze individual consumption patterns, computed as:

Mean Deviation: $\mu=\sum_{i} \frac{\left(x_{r}-\hat{x}_{r}\right)}{N}$; Standard Deviation: $\sigma=\sqrt{\sum_{i} \frac{\left(x_{r}-\hat{x}_{r}\right)^{2}}{N}} \quad$ where $x_{r}$ denotes actual consumption of agent $r ; \hat{x}_{r}$ denotes competitive equilibrium consumption of agents $r$ and $\mathrm{N}$ is the number of observation (consumers times experiments), thus $\mathrm{N}=30$.

Table 8 reports values of these for the five periods. Individual consumptions in period $t$ are pooled across experiments and the difference between the observed and predicted consumption value for period $t(t=$ $1 \ldots 5)$ computed for goods $X, Y$ and $Z$. In this way one can observed whether individual consumption levels converge to the equilibrium consumption values as period $j$ is replicated.

Table 8: Deviations of Individual's Holding from CRM Predictions (by period)

\begin{tabular}{clrrrrr}
\hline & & \multicolumn{5}{c}{ Period } \\
\hline Output & Statistics & 1 & 2 & 3 & 4 & 5 \\
& Mean Deviation & -2 & -1.07 & -1.1 & -1.47 & -1.08 \\
$X$ & Standard Deviation & 4.75 & 3.33 & 3.02 & 3.41 & 1.9 \\
& Mean Deviation & -2.3 & -2.8 & -2.6 & -2.5 & -1.16 \\
$Y$ & Standard Deviation & 5.24 & 6.46 & 5.9 & 5.7 & 2.74 \\
& Mean Deviation & -1.93 & -2.7 & -2.63 & -2.56 & -1.43 \\
& Standard Deviation & 4.85 & 6.14 & 5.96 & 5.9 & 3.7 \\
\hline
\end{tabular}


Evidence of convergence requires that the absolute value of the mean deviations and standard deviation in later periods are smaller than that of the early periods. From table 6 , the mean deviation of period 5 is $1.08,1.16$ and 1.43 for $X, Y$ and $Z$ respectively, the lowest of all observed periods. Furthermore, the mean deviation from the competitive value falls consistently over the first three periods for $X$ and the second four periods for $Y$ and $Z$. Standard deviations fall consistently over the first three periods for $X$ and the second four periods for $Y$ and $Z$. Standard deviations of later periods are lower than early periods, falling consistently for good $Y$ and $Z$. The hypothesis that the absolute deviations for the early period are smaller or equal to that of late periods (period 3-5) can be accepted at the 5\% level of significance, providing support for convergence towards the individual competitive equilibrium consumption level.

\section{Result 5: Output prices are not converging toward the competitive equilibrium.}

From table 4, it is observed that the asymptote of price of $X$ is 327.2 francs. Thus, evidence of strong convergence as $B_{2}$ 's are statistically different from the predictions of the CRM model is not found. Also, there is no evidence of weak convergence. Similar observations are made for prices of $Y$ and $Z$ at the $5 \%$ level of significance. The observed asymptote of price of $Y$ is 491.1 francs. As such, $B_{2}$ is statistically different from the CRM prediction of 360 francs. The asymptote of price of $Z$ is 476.7 francs. It does not tend to converge towards the equilibrium of 390 francs. Also, there is no indication of weak convergence in either price of $Y$ or $Z$. Thus, there is non-existence of price convergence toward the competitive equilibrium.

\section{Result 6: Input/ Output prices ratios are below the marginal revenue product.}

As pointed out by Noussair et al (1995), determinations of input prices are more complex because of the nature of derived demand. As such, deviation of input prices from the competitive equilibrium is not only due to a lack of equilibrium in the output market; but the factors have their own independent dynamic adjustment. Under the CRM conditions it is expected input prices to equal output prices multiplied by the marginal physical product, which is a constant as technologies are linear. It means that the ratio of factor price to output price, when compared to the marginal physical products, can then be used to determine whether the input conditions are satisfied.

Table 9: Convergence Patterns Input/Output Price Ratios

\begin{tabular}{|c|c|c|c|c|c|c|c|c|c|c|c|}
\hline \multirow[t]{2}{*}{$\begin{array}{l}\text { Dependent } \\
\text { Variables }\end{array}$} & \multirow[t]{2}{*}{$B_{11}$} & \multirow[t]{2}{*}{$B_{12}$} & \multicolumn{8}{|c|}{ 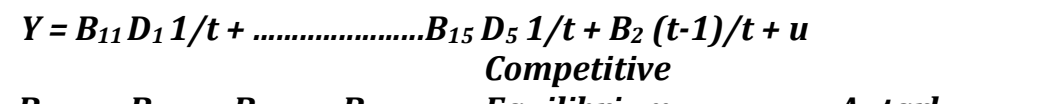 } & \multirow[t]{2}{*}{$\mathbf{R}^{2}$} \\
\hline & & & & & & & Predictions & Sig & Predictions & Sig & \\
\hline \multicolumn{12}{|l|}{ Country 1} \\
\hline$P_{L} / P_{x}$ & $\begin{array}{l}5.09 \\
9.97\end{array}$ & $\begin{array}{l}2.8 \\
2.5\end{array}$ & $\begin{array}{l}2.37 \\
0.85\end{array}$ & $\begin{array}{l}0.92 \\
1.23\end{array}$ & $\begin{array}{l}2.26 \\
1.59\end{array}$ & $\begin{array}{l}2.48 \\
1.31\end{array}$ & 4 & ns & 4 & ns & 0.62 \\
\hline \multicolumn{12}{|l|}{ Country 2} \\
\hline$P_{L} / P_{Y}$ & $\begin{array}{l}1.77 \\
2.45\end{array}$ & $\begin{array}{r}2.84 \\
1.7\end{array}$ & $\begin{array}{r}0.98 \\
0.717\end{array}$ & $\begin{array}{r}1.5 \\
0.58\end{array}$ & $\begin{array}{l}1.84 \\
0.41\end{array}$ & $\begin{array}{l}1.59 \\
0.38\end{array}$ & 3 & $<0.05$ & 3 & $<0.05$ & 0.88 \\
\hline \multicolumn{12}{|l|}{ Country 3} \\
\hline$P_{L} / P_{Z}$ & $\begin{array}{r}4.1 \\
1.38\end{array}$ & $\begin{array}{c}2.88 \\
0.26\end{array}$ & $\begin{array}{c}2.36 \\
0.78\end{array}$ & $\begin{array}{r}1.63 \\
0.2\end{array}$ & $\begin{array}{c}2.37 \\
0.32\end{array}$ & $\begin{array}{c}2.13 \\
0.28\end{array}$ & 3 & $<0.05$ & 3 & $<0.05$ & 0.92 \\
\hline
\end{tabular}

Table 9 reports estimates of the time path of ratios of output to input prices. An econometric model of the same form as described in section 5.4 is estimated. The $B_{1 i}$ in this case measures the ratio during the first period which is permitted to differ among experiments. $B_{2}$ measures the asymptote of each ratio as time goes to infinity. Evidence of convergence requires that $B_{2}$ is not statistically different from the ratio of factor price to output price. Thus there is evidence of strong convergence for country 1 as $B_{2}$ is not statistically different from the ratio of factor price to output price. Neither strong nor weak evidence are found for countries 2 and 3 .

A similar relationship was found in the economies studied by Noussair et al (1995). This relationship also emerged in the laboratory economy created by Riedl and Van Winden (2001). Noussair et al (1995) give the Risk Compensated Input/ Output Price Adjustment Property as an explanation of this observation. 
Unlike the consumers, producers do not have a cost sheet to give them an idea about the reservation price they should pay for the labour they bought. This implies that they do not have a prior idea about the price they will change for the final product. Thus, they face a risk. To compensate for this risk, producers earned a premium over the amount they will earn in the competitive equilibrium. Although there is evidence of strong convergence in the case of country 2 and country 3 , the observed marginal physical products tend to be lower than the predicted value as the number of periods increase, hence it can argue that this property is also present in countries 2 and 3.

\section{Efficiency}

Finally, to calculate the level of efficiency in a particular period, a comparison of the total amount of profits made by both Type $\mathrm{C}$ and Type $\mathrm{P}$ traders as a percentage of the maximum profit that can be earned at competitive equilibrium is done.

\section{Observation 1: Efficiency is higher in later sessions than earlier}

Market efficiency for the pooled data is reported in Figure 5. Efficiency in early periods is lower than that of late periods. Efficiency in periods $1-3$ averaged $61.6 \%$ whereas efficiency in periods $4-5$ averaged $70.3 \%$. Efficiency level in period 5 is $76.6 \%$.

\section{Figure 5: Market System Efficiency}

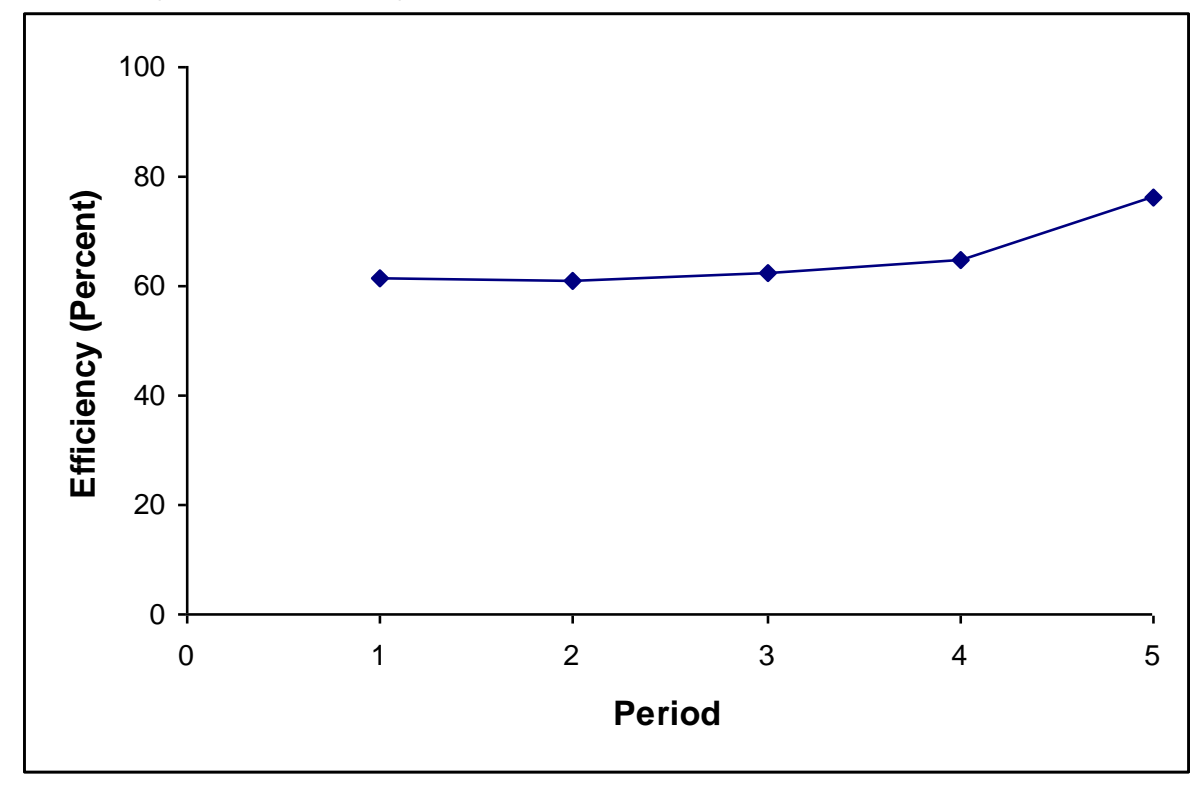

\section{Conclusions}

The generalisation of the CRM to a three by three setting was illustrated by Jones (1961). He provided a complete specification of the patterns of specialisation and trade in the CRM with many goods and countries. He showed an efficient assignment of countries to goods in a many-good, many-country CRM require minimisation of the product of countries' unit labour requirements. Specialisation is associated with low unit labour requirements where "low" must be interpreted in comparison to other goods since the model requires that each country produce something, and thus contributes at least one of its labour requirements to one of these goods.

Although the theoretical model satisfies this condition, the main conclusion of the experiments is that comparative advantage holds for trade patterns in one but not all countries. The competitive model is rejected as a representation of the experimental data. Convergence is present in 6 out of the 12 quantity variables and 2 out of the 6 price variables. There is no convergence (strong or weak) in output prices whereas there is also a tendency for factors of production to trade at prices below their marginal products. There is less support for the autarky model. While, Noussair et al (1995) observe comparative advantage motivated by the $2 \times 2$ CRM in a laboratory setting, the results reveal that when there is an increase the dimensionality from $2 \times 2$ to a $3 \times 3$, the laboratory data is not consistent with the law of 
comparative advantage. As such, the robustness of comparative advantage is fragile when both the number of goods and countries are increased, at least in this laboratory setting.

\section{Acknowledgements}

The author thanks David Greenaway, Ray Riezman, Chris Starmer, Tony Wheatman, Laurent Muller and Simon Atack for helpful comments.

\section{References}

Asheghian, P. \& Saidi, R. (1999). Commodity Concentration and Export Earning Instability: The Case of Venezuela. Development Policy Review, 17: 419-427.

Chen, K. Y. \& Plott, C. R. (2002). Information Aggregation Mechanisms: Concept, Design and Implementation for a Sales Forecasting Problem, Social Science Working Paper No. 1131. California Institute of Technology.

Deardorff, A. (2005). How Robust is Comparative Advantage, Review of International Economics. 13: 10041016.

Gjerstad, S. \& Dickhaut, J. (1998). Price Formation in Double Auctions, Games and Economic Behavior, 22: 1-29.

Gode, D. K. \& Sunder, S. (1989). Human and Artificially Intelligent Traders in Computer Double Auctions. Working Paper, Meetings of the Economic Science Association, Tucson, Arizona.

Goodfellow, J. \& Plott, C. R. (1990). An Experimental Examination of the Simultaneous Determination of Input Prices and Output Prices, Southern Economic Journal, 56: 969-983.

Jones, R. W. (1961). Comparative Advantage and the Theory of Tariffs: A Multi-Country, Multi-Commodity Model. Review of Economic Studies, 28: 161-175.

Jones, R. W. (1985). Ricardo-Graham World Transformation Surfaces, Osaka City University Economic Review, 20: 27-33.

Lian, P. \& Plott, C. R. (1998). General Equilibrium, Markets, Macroeconomics and Money in a Laboratory Experimental Environment. Economic Theory. 12: 21-76.

Love, R. (1986). Commodity Concentration and Export Earnings Instability, A Shift from Cross-section to Time Series Analysis. Journal of Development Economics, 24: 239-248.

McKenzie, L. W. (1954). Specialisation and Efficiency in World Production, Review of Economic Studies, 21: 165-180.

Noussair, C. N., Plott C., R. \& Riezman R., G. (1995). An Experimental Investigation of the Patterns of International Trade. American Economic Review, 85: 462-491.

Noussair, C. N., Plott C. R. \& Riezman, R. G. (2007). Production, Trade, Exchange Rates and Equilibration in Large Experimental Economies. European Economic Review, 51: 49-76.

Noussiar, C. N. \& Powell O. (2008). Peak and Valleys: Experimental Asset Markets with Non-Monotonic Fundamentals. Discussion paper 2008-49. Tilburg University.

Plott, C. R. (1991). A Computerized Laboratory Market System and Research Support Systems for the Multiple Unit Double Auction. Working Paper No. 783, California Institute of Technology.

Plott, C. R. \& Gray P. (1990). The Multiple Unit Double Auction. Journal of Economic Behavior and Organization, 13: 245-258.

Riedl, A. \& Winden F. V (2001). Does the Wage Tax System cause Budget Deficits? Public Choice, 109: 371394.

Smith, V. L. (1962). An Experimental Study of Competitive Market Behavior. Journal of Political Economy, 70: 111-137. 


\begin{tabular}{|c|c|c|c|c|c|c|c|}
\hline Consumer 1 & Unit & X Unit & X Total & Y Unit & Y Total & Z Unit & Z Total \\
\hline & & Value & Value & Value & Value & Value & Value \\
\hline & 1 & 600 & 600 & 640 & 640 & 680 & 680 \\
\hline & 2 & 510 & 1110 & 550 & 1190 & 590 & 1270 \\
\hline & 3 & 420 & 1530 & 460 & 1650 & 500 & 1770 \\
\hline & 4 & 330 & 1860 & 370 & 2020 & 410 & 2180 \\
\hline & 5 & 240 & 2100 & 280 & 2300 & 320 & 2500 \\
\hline & 6 & 150 & 2250 & 190 & 2490 & 230 & 2730 \\
\hline & 7 & 60 & 2310 & 100 & 2590 & 140 & 2870 \\
\hline & 8 & 10 & 2320 & 10 & 2600 & 50 & 2920 \\
\hline \multirow[t]{10}{*}{ Consumer 2} & Unit & X Unit & X Total & Y Unit & Y Total & Z Unit & Z Total \\
\hline & & Value & Value & Value & Value & Value & Value \\
\hline & 1 & 555 & 555 & 595 & 595 & 635 & 635 \\
\hline & 2 & 465 & 1020 & 505 & 1100 & 545 & 1180 \\
\hline & 3 & 375 & 1395 & 415 & 1515 & 455 & 1635 \\
\hline & 4 & 285 & 1680 & 325 & 1840 & 365 & 2000 \\
\hline & 5 & 495 & 2175 & 235 & 2075 & 275 & 2275 \\
\hline & 6 & 105 & 2280 & 145 & 2220 & 185 & 2460 \\
\hline & 7 & 15 & 2295 & 55 & 2275 & 95 & 2555 \\
\hline & 8 & 5 & 2300 & 20 & 2295 & 50 & 2605 \\
\hline
\end{tabular}

\section{Appendix 2}

\section{Instructions-Type P/ Type C}

You are participating in an experiment of market decision making. The instructions are simple and if you follow them you can earn considerable amount of money which will be paid to you in cash. In this experiment, we are conducting a market in which you will be designated as one of two types of traders: Type $C$ or Type $P$. The experiment will run for 5 periods of 10 minutes each. You can find your type at the top of the instructions. You are classified as Type P and you are given a Record Sheet for each period of the experiment and a Production Schedule Sheet (these are on your desk). The Production Schedule Sheet will help you determine the value of any decision that you might make. This information is private to you and should not be revealed to anyone.

There are 4 types of goods (one input and three outputs) which can be traded in these markets: $\mathrm{W}, \mathrm{X}, \mathrm{Y}$ and Z. You can make profits through trading of the goods. Unlike the practice session (practice 2) where you were allowed to buy and sell in the same market, here in each market you can either buy or sell but not both. When you move the order box between market you will see either F1-BUY if you are a buyer or F2-SELL if you are a seller. Trading in all markets is in terms of francs; however your final payoff will be in terms of pounds. Your conversion rate is 4000 francs to $£ 1$ (for every 4000 francs profits you make, you earn £1). You will be paid at the end of the experiment according to how much profit you make. In this handout it is explained how to calculate profits

\section{Endowments/ Cash on Hand}

At the beginning of the experiment you will receive 100000 francs cash on hand. At the beginning of each period, you will be given an endowment of W. This is the same for each period. However, you are free to buy more endowment from anyone who might want to sell it.

\section{How the System Works}

Type $\mathrm{C}$ traders are endowed with $\mathrm{W}$ but would like to consume $\mathrm{X}, \mathrm{Y}$ and $\mathrm{Z}$. They can sell $\mathrm{W}$ to Type $\mathrm{P}$ to increase their cash in order to buy $\mathrm{X}, \mathrm{Y}$ and $\mathrm{Z}$. Thus, Type $\mathrm{C}$ is a seller in market for $\mathrm{W}$ and buyer in market for $\mathrm{X}, \mathrm{Y}$ and $\mathrm{Z}$. Type $\mathrm{P}$ traders are also endowed with $\mathrm{W}$, but they may purchase units of $\mathrm{W}$ from Type $\mathrm{C}$ traders in order to produce. They can produce $\mathrm{X}, \mathrm{Y}, \mathrm{Z}$ from $\mathrm{W}$ and sell them to Type $\mathrm{C}$ traders to increase their cash on hand. Thus, Type $\mathrm{P}$ is a buyer in market for $\mathrm{W}$ and seller in market for $\mathrm{X}, \mathrm{Y}$ and $\mathrm{Z}$. 


\section{Specific instructions to type $p$}

\section{Production}

During each market period, you are free to buy as many units of $\mathrm{W}$ which you use to produce and sell units of $\mathrm{X}, \mathrm{Y}$ and $\mathrm{Z}$ from units of $\mathrm{W}$. Production is done by using the transformation key F4 (as you were shown in practice training session). When producing units of $\mathrm{X}, \mathrm{Y}$ and $\mathrm{Z}$, you have to use the table labelled Production Schedule. This table reflects the number of units of $\mathrm{X} / \mathrm{Y}$ and $\mathrm{Z}$ that you can produce from given amounts of $\mathrm{W}$ for the whole period. You have already been instructed in how to read the production schedule, but the following example may remind you further. Note that you have to fill the transformation box (F4) based on the production schedule.

\section{Production Schedule (for Production Decision)}

\begin{tabular}{|c|c|c|c|c|c|c|c|c|c|c|}
\hline Units of W (Input) & 1 & 2 & 3 & 4 & 5 & 6 & 7 & 8 & 9 & 10 \\
\hline Units of X (Output) & 6 & $4 \cdot$ & 24 & (4) & 9 & Q1 & (a) & 0 & 0 & 0 \\
\hline Total Outnut & 6 & 10 & 12 & 12 & 12 & 12 & 12 & $\Delta_{12}$ & 12 & 12 \\
\hline & & & & & & & & & & \\
\hline
\end{tabular}

\begin{tabular}{|c|c|c|c|c|c|c|c|c|c|c|}
\hline Units of W (Input) & 1 & 2 & 3 & 4 & 5 & 6 & 7 & 8 & 9 & 10 \\
\hline Units of Y (Output) & $5)$ & 3 & $2+$ & 11 & Q & (0) & (a) & 0 & 0 & 0 \\
\hline & 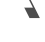 & H. & H & dive & $\sqrt{4}$ & 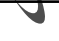 & $\sqrt{17}$ & & & \\
\hline Total Output & 5 & 8 & 10 & 11 & 11 & 11 & 11 & $\$ 11$ & 11 & 11 \\
\hline
\end{tabular}

\begin{tabular}{|c|c|c|c|c|c|c|c|c|c|c|}
\hline Units of W (Input) & 1 & 2 & 3 & 4 & 5 & 6 & 7 & 8 & 9 & 10 \\
\hline Units of Z (Output) & 7 & $5)$ & 4 & 21 & d) & a) & b & a) & 0 & 0 \\
\hline & $\sqrt{5}$ & 2 & in & 28 & at & iv & a & $\lambda$ & & \\
\hline Total Output & 7 & 12 & 16 & 18 & 18 & 18 & 18 & 18 & 18 & 18 \\
\hline
\end{tabular}

Suppose you have two units of W. Based on the above production schedule, you can produce one of these combinations:

1. 10 units of $X$ (first unit produces 6 and the second produces 4)

2. 6 units of $X$ and 5 units of $Y$

3. 6 units of $X$ and 7 units of $Z$

4. 5 units of $Y$ and 7 units of $Z$

5. 8 units of $Y$ (first unit produces 5 and the second produces 3 )

6. 12 units of $\mathrm{Z}$ (first unit produces 7 and the second produces 5)

You make profit by selling those units of X/Y and Z produced to Type $\mathrm{C}$ traders. For example assume you produce 1 unit of $X$ (using 1 unit of $W$ ) which is sold to Type $C$ trader at 180. If the purchase price of $W$ was 150 , then you make a per-unit profit of $180-150=30$. Thus, your profit on par unit sold is (Selling price- Cost [Buying price of W]. 


\section{Trading Profit}

You can earn profit through trading and consumption. Selling increases your cash on hand by the amount of total sales revenue. Buying decreases your cash in hand by the value of purchases.

\section{Earnings}

Your profit per period is equal to:

(Cash in hand at the end of the period) - (Cash in hand at the beginning of the period)

At the end of each period you must complete a record sheet.

\section{Record Sheet}

\section{Trading}

Period No:

(1) Cash on hand at end of the period

(2) Cash on hand at beginning of period

(3) Net Change in cash on hand (1) - (2)

\section{Total Profits for the Period}

In line (1) fill the cash on hand at the end of the period. In line (2) fill the cash on hand at the beginning of the period. Line (3) is simply line (1) minus line (2) which is your net change in cash on hand and also your total profits for the period.

\section{Market Restrictions}

Some of you may not be able to trade in all markets. You may not trade in Market No: 4, 5, 6, 7, 8, 9, 11, 12

\section{Specific instructions to type c}

\section{Consumption}

During the experiment you are free to sell as many units as you wish of $\mathrm{W}$ and buy as many units of $\mathrm{X}, \mathrm{Y}$ and $\mathrm{Z}$ as you wish. Each unit of $\mathrm{X}, \mathrm{Y}$ and $\mathrm{Z}$ you buy is assumed to be consumed by you.

Your Redemption Value sheet determines the amount you receive through consumption. You have already been instructed in how to read the redemption value sheet in the practice session. For the first unit of $\mathrm{X}$ that you consume for a given trading period, you receive the amount listed on your Redemption Value Sheet - the first row in the X unit value column (500, for example). For the second unit of X that you consume, you receive the amount listed in second row of the $\mathrm{X}$ unit value column ( 480 for example). The total amount that you receive from the consumption of both is found in the second column of $X$ total value column $(500+480=980)$. The amount you receive from consumption of $Y$ and $Z$ are found in a similar way by reading the final 4 columns. The redemption value you received from $\mathrm{W}$ is always zero. Whenever you trade you should take account of those redemption values. Your per unit profit is given by: (redemption value- purchase price).

Redemption Value Sheet- in francs (for Consumption Decisions)

\begin{tabular}{|l|l|l|l|l|l|l|}
\hline Unit & X unit & X total & Y unit & Y tota & Z Unit & Z total \\
& Value & Value & Value & Value & Value & Value \\
\hline 1 & 500 & 500 & & & & \\
\hline 2 & 480 & 980 & & & & \\
\hline 3 & 5 & & 1 & Id & & \\
\hline 4 & & & & &
\end{tabular}




\section{Instructions to both types \\ Trading profits}

You can earn profits through consumption and trading. Selling increases your cash on hand by the amount of total sales revenue. Buying decreases your cash in hand by the value of purchases.

\section{Earnings}

Your profits per period exactly is equal to

(Cash in hand at the end of the period) - (Cash in hand at the beginning of the period) + (Redemption value of units that you consume).

At the end of each period you must complete a record sheet.

\section{Record Sheet}

\section{Trading}

\section{Period No:}

(1) Cash on hand at end of the period

(2) Cash on hand at beginning of the period

(3) Net Change in cash on hand (1) - (2)

\section{Consumption}

(4) Units Consumed: X

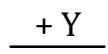

$+\mathrm{Z}$

Earnings from consumption

(5) $\mathrm{X}$

(6) $\mathrm{Y}$

(7) $\mathrm{Z}$

(8) Total Earnings from consumption

$(5)+(6)+(7)$

Total Profits for the Period: (3) + (8)

Your record sheet is divided into two sections: Trading and Consumption. In line (1) fill the cash on hand at the end of the period. In line (2) fill the cash on hand at the beginning of the period. Line (3) is simply line (1) minus line (2). In line (4) enter the number of units that you consume of W, X, Y and Z. In line (5) (7), fill in the earnings from the consumption $\mathrm{X}, \mathrm{Y}$ and $\mathrm{Z}$ and $\mathrm{Y}$ based on your redemption values sheet. In line (8) add the total of lines (5), (6) and (7). In line (9) add the total of line (3) and (8), this is your profit for the period (in francs). You should aim to maximise your profits since this value will determines your earnings at the end of the experiment.

\section{Market Restrictions}

Some of you may not be able to trade in all markets. You may not trade In Market 11 and Market 12. 